\title{
Journal of Civil and Environmental Engineering: Editorial
}

\author{
Manjunath SV* \\ Department of Civil Engineering, Indian Institute of Technology, Madras, Chennai, Tamil Nadu, India
}

\section{Abstract}

The Journal of Civil and Environmental Engineering (ISSN: 2165-784X) is an international peer-reviewed journal that emphasizes multidisciplinary aspects of environmentally sustainable civil engineering mechanisms, practices, tools and techniques through its open-access platform. The journal represents a platform for the experts and emerging researchers to communicate their scientific knowledge related to fundamentals and advanced methodologies, tools and techniques in civil and environmental engineering.

\section{Introduction}

The Journal of Civil and Environmental Engineering offers broad publication of original research articles emphasizing on providing sustainable solutions comprising of innovative ideas, methodologies and technologies unfolding significant novel findings addressing the current global issues and concerns prevailing in the forefront areas of civil and environmental engineering. The review articles mainly focussing sustainable solutions to current challenges and case studies illustrating the fundamentals, novel theory and its application to innovative practice are considered for publication. Further, short communications demonstrating novel methodologies and experimental work, commentaries related to published articles and letters to editors are considered for publication in this journal.

The Journal of Civil and Environmental Engineering encourages and publishes articles involving the construction and development of novel, groundbreaking technologies, products and innovative ideas that provide sustainable solutions to existing problems in forefront areas. This journal focuses on two aspects: civil engineering and environmental science and engineering. Within the Journal of Civil and Environmental Engineering, the civil engineering aspect deals with the diverse group of civil engineering sectors involving smarter planning, design, cleaner construction, operation and maintenance techniques for all types of infrastructure related to architectural and structural engineering, transportation engineering, geotechnical engineering and building materials and construction management.

Besides, within the Journal of Civil and Environmental Engineering, the environmental engineering aspect deals with the design and development of innovative and sustainable technologies for environmental protection. The scope of this journal extends to surface and groundwater quality monitoring, physico-chemical and biological techniques for water and wastewater treatment, cleaner and zero liquid discharge technologies for industrial wastewater treatment, membrane technologies for desalination of seawater and brackish water, synthesis, characterization and application of novel nanomaterials, advanced oxidation processes involving photocatalysis, sonication, ozonation and microwave techniques for removal of micro-organic pollutants, abatement of organic and inorganic pollutants and emerging contaminants removal.
Besides, articles related to hazardous waste management strategies, water resource management, air pollution control and management, toxicity analysis, novel analytical methodologies, resource and energy reuse, recovery and recycling, soil and groundwater remediation, climate change, environmental impact assessment, environmental life cycle assessment and strategies for environmental sustainability and human health issues are considered for publication in this journal.

The Journal of Civil and Environmental Engineering is associated with Hilaris Group for archiving, maintenance, commercial purpose and other technical support. Accordingly, Google Analytics Metrics displays that the readership metrics of the Journal of Civil and Environmental Engineering have amplified when associated with the Hilaris group. Besides, the journal preserves and upholds the website (https://www.hilarispublisher.com/civilenvironmental-engineering.html) for manuscript submission, editorial and peer-review process for publishing the articles online.

As a whole, the time taken for peer-reviewing of the articles is short and processing of accepted articles in the Journal of Civil and Environmental Engineering is rapid. The publication will appear online as well as print versions within the prescribed timeline. Subsequently, the scientific articles published in the Journal of Civil and Environmental Engineering considered for indexing/ abstracting by Index Copernicus, Google Scholar, Electronic Journals Library and Open J Gate. Additionally, Virtual Library of Biology (vifabio), SWB online catalog, OCLC-WorldCat, EBSCO A-Z, Hamdard University, RefSeek, Ulrich's Periodicals Directory, Genamics Journal Seek and Sherpa Romeo also ensure indexing/abstracting the articles published in this journal.

The editorial team led by Editor-in-Chief (Berrin Tansel) has been putting the greatest efforts to make the Journal of Civil and Environmental Engineering a high-impact international journal. Further, the author would like to express the most profound appreciation to all the authors and reviewers who have made treasured contributions to this journal by sharing their expertise and knowledge. The author also wants to show sincere appreciation to the Editorin-Chief, editorial board members, journal advisory body members, journal coordinators, journal managers and publisher (Hilaris) for their valuable support in publishing the current volume of the Journal of Civil and Environmental Engineering.

\begin{abstract}
*Address for Correspondence: Manjunath SV, Department of Civil Engineering Indian Institute of Technology, Madras, Chennai, Tamil Nadu, India, E-mail: manju.vallabha@gmail.com

Copyright: (C) 2020 Manjunath SV. This is an open-access article distributed under the terms of the creative commons attribution license which permits unrestricted use, distribution and reproduction in any medium, provided the original author and source are credited.
\end{abstract}

Received 21 April, 2020; Accepted 24 April, 2020; Published 30 April, 2020
How to cite this article: Manjunath SV. "Journal of Civil and Environmental Engineering: Editorial." Civil Environ Eng 10 (2020): 342 doi: 10.37421/ jcee.2020.10.342 